\title{
Gastrointestinal stromal tumor and other primary metachronous or synchronous neoplasms as a suspicion criterion for syndromic setting
}

\author{
GIOVANNI PONTI ${ }^{1}$, GABRIELE LUPPI ${ }^{1}$, DAVIDE MARTORANA ${ }^{4}$, GIULIO ROSSI ${ }^{2}$, \\ LORENA LOSI $^{2}$, FEDERICA BERTOLINI ${ }^{1}$, GIULIANA SARTORI ${ }^{2}$, GIOVANNI PELLACANI ${ }^{3}$, \\ STEFANIA SEIDENARI ${ }^{3}$, ELISA BONI $^{3}$, TAURO MARIA NERI $^{4}$, ENRICO SILINI $^{5}$, \\ ELISA TAMBURINI $^{5}$, ANTONIO MAIORANA $^{2}$ and PIER FRANCO CONTE ${ }^{1}$
}

\author{
${ }^{1}$ Department of Oncology and Haematology, ${ }^{2}$ Section of Pathologic Anatomy, ${ }^{3}$ Division of Dermatology, \\ University of Modena and Reggio Emilia, Modena; ${ }^{4}$ Molecular Genetics Unit, Universitary-Hospital of Parma, \\ ${ }^{5}$ Department of Pathology and Laboratory Medicine, Section of Pathological Anatomy, University of Parma, Parma, Italy
}

Received July 24, 2009; Accepted October 9, 2009

DOI: $10.3892 /$ or_00000653

\begin{abstract}
Gastrointestinal stromal tumors (GISTs) may be sporadic or inherited. Although KIT and PDGFRA activating mutations are the oncogenic mechanisms in most sporadic and inherited GISTs, a small subset of GISTs are negative for both. Besides the classical Familial GIST Syndrome, GIST can occur as part of multi-neoplastic disease. The present study was designed to analyze the synchronous and metachronous tumors developed among GIST patients assessed by our institution for GIST Syndrome setting recognition. Patients $(n=141)$ with primary GIST ( 77 men and 64 women) were recruited between 1988 and 2007 and their clinical and pathological records were reviewed. Mutation analysis of KIT, PDGFRA, NF1 and MMR genes was performed on somatic and peripheral blood DNA. GISTs occurred associated with other primary malignancies in 46 of 141 (32.6\%) patients. The most common neoplasms were gastrointestinal and genitourinary. A novel exon 6 germline large deletion of NF1 was identified in the NF1/ GIST kindred. The development of GIST associated with other neoplasms is common and diagnosis of peculiar benign associated-neoplasms warrants the search for familial cancer susceptibility. In particular, syndromic or familial settings have to be suspected in the presence of neurofibroma or lung chordoma in C-KIT and PDGFRA negative GIST patients.
\end{abstract}

Correspondence to: Dr Giovanni Ponti, Department of Oncology and Haematology, University of Modena and Reggio Emilia, via del Pozzo 7, 41100 Modena, Italy

E-mail: ponti.giovanni@unimo.it

Key words: gastrointestinal stromal tumors, NF1, familial cancer, neurofibroma, chordoma

\section{Introduction}

Gastrointestinal stromal tumor (GIST) represents the most common intramural mesenchymal tumor of the gastrointestinal tract. It originates from primitive cells with the same characteristics as interstitial cells of Cajal (ICC) and occurs predominantly in the stomach $(70 \%)$ and small intestine (10-20\%) (1). Histologically, GISTs show spindle cell (70\%), epithelioid (20\%) or mixed morphology (10\%) (2). Activating mutations in KIT $(75-80 \%)$ or platelet-derived growth factor receptor $\alpha$ (PDGFRA) $(<10 \%)$ are the most common oncogenic events in GIST $(3,4)$; a small subset of GISTs, with otherwise typical clinicopathological features, are negative for both C-KIT and PDGFR mutations. GIST may be sporadic or inherited in an autosomal-dominant (AD) manner either alone or in association with other rare neoplasms $(5,6)$ where three distinct Syndromic GISTs are clinically and in part biomolecularly characterized. In the classical Familial GIST Syndrome, multiple members develop numerous GISTs in a background of ICC hyperplasia. In these families, the GIST tumors are inherited in an AD pattern of inheritance due to activation of KIT or PDGFRA germline mutations (7). In addition, GIST syndrome has been described as Carney triad disease characterized by at least two of the following rare neoplasms: multicentric functioning extra-adrenal paraganglioma, pulmonary chondroma and multifocal epithelioid GIST of the stomach (8). In most cases, the Carney triad is incomplete and is not normally related to activating mutations in common hot spots of C-KIT or PDGFR. An association between the development of GISTs and type 1 neurofibromatosis (NF1) has also been established (9). NF1 is an autosomal-dominant genetic disorder caused by alteration of the NF1 gene and affecting 1/3500 individuals worldwide. The main clinical features of the disease are café-au-lait spots, freckling and benign peripheral nerve sheath tumors or neurofibromas (10). Despite genetic analysis revealing that most GISTs arising in the setting of NF1 are not related to KIT or PDGFRA but to the inactivation of NF1, a large study 
Table I. Details of antibodies used for immunohistochemical analysis of the gastrointestinal stromal tumors.

\begin{tabular}{llll}
\hline Antibody (clone or catalog number) & \multicolumn{1}{c}{ Source } & Dilution & Antigen retrieval \\
\hline CD117 (pAb,\#A4502) & Dako (Glostrup, Denmark) & $1: 200$ & None \\
S-100 (pAb, \#RB044-A) & NeoMarkers (Fremont, CA) & $1: 5$ & None \\
Smooth-muscle actin (mAb, 1A4) & Biogenex (San Ramon, CA) & $1: 20$ & None \\
Desmin (mAb, D33) & Dako (Hamburg, Germany) & $1: 10$ & MW \\
CD34 (mAb, QB-END/10) & Novocasta (Newcastle upon Tyne, UK) & $1: 40$ & MW \\
PDGFR-A (pAb, \#sc-338) & Santa Cruz Biotechnology (Santa Cruz, CA) & $1: 200$ & MW \\
\hline
\end{tabular}

pAb, polyclonal antibody; mAb, monoclonal antibody; PDGFR, plateled-derived growth factor receptor; MW, microwave treatment.

proved that $8 \%$ had KIT mutations and $6 \%$ had PDGFRA mutations (15). Recently, the identification of a germline PDGFRA mutation in a kindred affected by a rare intestinal neurofibromatosis (NF3) showed that this rare disease is a subtype of Familial GIST (11). However, further study is required on the molecular basis underlying GIST development in neurofibromatosis as well as in other syndromic settings, and whether there is a difference in the molecular pathogenesis of sporadic GISTs and GISTs associated with multi-neoplastic disease.

The aim of the present study was to analyze the spectrum and clinico-pathological features of synchronous and metachronous GIST-associated neoplasms among patients from a single institution in order to evaluate their impact on recognition of Familial Syndrome setting.

\section{Materials and methods}

Patients ( $\mathrm{n}=141)$ with primary GIST (77 men and 64 women) were referred to our institution between 1988 and 2007. Immunohistochemical examinations were performed on material fixed in buffered formalin and embedded in paraffin. In addition to assessment of CD117 and PDGFRA in tumor cells, reactions with CD34, SMA, and S-100 proteins were also studied. Mutation analysis of KIT, PDGFR, NF1 and MMR genes was performed on somatic and peripheral blood DNA. According to the diagnostic criteria of Warren and Gates (13), a double cancer is classified as a metachronous type when the GIST was identified less than 1 year before or after the other neoplasms.

Immunohistochemical analysis. In each case, sections $(3 \mu \mathrm{m})$ were obtained from a representative block. Sections were airdried overnight at $37^{\circ} \mathrm{C}$, then deparaffinized in xylene and rehydrated through a decreasing concentration of alcohol to water. Endogenous peroxidase activity was blocked by immersion for 10 min with $3 \%$ hydrogen peroxide $\left(\mathrm{H}_{2} \mathrm{O}_{2}\right)$ in methanol. Immunostaining was accomplished with a modified streptavidin-biotin-peroxidase technique using an automated immunostainer (Benchmark, Ventana, Tucson, AZ, USA); 3' 3-diaminobenzidine was used as the chromogen and Harris's hematoxylin as the counter-stain. The antibodies used in the study and their technical characteristics are summarized in Table I. Negative and positive controls were included in each batch.

The percentage of positive cells and the intensity of staining ( 0 , negative; $1+$, weak; $2+$, moderate; $3+$, strong) were recorded, and a tumor was considered positive when at least $10 \%$ of the neoplastic cells reacted with a moderate intensity or greater on the relevant subcellular localization.

Mutational analysis. Sections $(5 \mu \mathrm{m})$ obtained from a representative paraffin-embedded block were deparaffinized with xylene, and tumor DNA was extracted using a manual microdissection method. Micro-dissected tumor cells were subjected to proteinase $\mathrm{K}$ treatment in a digestion buffer [50 mM Tris (pH 8.5), $1 \mathrm{mM}$ EDTA, 0.5\% Tween-20] and then incubated overnight at $56^{\circ} \mathrm{C}$. Polymerase chain reaction (PCR) was performed in $20 \mu 1$ reactions containing $2.0 \mu 1$ DNA, $2 \mu 1$ of commercial PCR buffer (Applied Biosystems, Foster City, CA, USA), 1.0-2.0 mM of $\mathrm{MgCl}_{2}, 200 \mu \mathrm{M}$ of each dNTP, 20 pmol of each primer, and 3 units of AmpliTaq Gold polymerase (Applied Biosystems). PCR was carried out on a Uno II Thermoblock (Biometra, Gottingen, Germany). Initial denaturation at $94^{\circ} \mathrm{C}$ for 10 min was followed by 41 cycles, and a final extension step $(7 \mathrm{~min}$ at $72^{\circ} \mathrm{C}$ ). The cycles included denaturation at $95^{\circ} \mathrm{C}$ for 1 min, annealing at $53-66^{\circ} \mathrm{C}$ for $1 \mathrm{~min}$, and extension at $72^{\circ} \mathrm{C}$ for $2 \mathrm{~min}$. The amplified DNA was electrophoresed on $2 \%$ agarose gel for $1 \mathrm{~h}$ at $110 \mathrm{~V}$. The amplification products were then purified using a MinElute PCR purification kit (Qiagen, Valencia, CA, USA) following the manufacturer's instructions and were sequenced in both directions on an ABIPrism 310 automatic sequencer (Applied Biosystems) using the Big Dye Terminator v1.1 Cycle Sequencing kit. The data were analyzed with the Sequencing Analysis 5.2 Software (Applied Biosystems). The forward and reverse oligonucleotide primers used to amplify $c$-kit exons $9,11,13,14$, 17 and PDGFR $\alpha$ exons 12,14, 18 are listed in Table II.

Mutation analysis of NF1 gene. Genomic DNA from the patient with neurofibromatosis type 1 (NF1) was extracted from peripheral blood using the QIAamp DNA Blood Mini Kit (Qiagen), and stored at $-20^{\circ} \mathrm{C}$ until use. All of the NF1 exons were amplified by PCR with intron spanning primers as described by De Luca et al (14) and analyzed with 
Table II. Oligonucleotide primers used in the study.

\begin{tabular}{|c|c|c|c|}
\hline Primer name & Primer sequence & $\begin{array}{l}\text { Annealing } \\
\text { temperature }\left({ }^{\circ} \mathrm{C}\right)\end{array}$ & $\begin{array}{l}\text { Product size } \\
\text { (bp) }\end{array}$ \\
\hline Exon $9 \mathrm{c}$-Kit & $\begin{array}{l}\text { Forward: 5'-ATG CTC TGC TTC TGT ACT GCC-3' } \\
\text { Reverse: 5'-CAG AGC CTA AAC ATC CCC TTA-3' }\end{array}$ & 58 & 238 \\
\hline Exon $11 \mathrm{c}-\mathrm{Kit}$ & $\begin{array}{l}\text { Forward: 5'-CTA TTT TTC CCT TTC TCC CC-3' } \\
\text { Reverse: 5'-TAC CCA AAA AGG TGA CAT GG-3' }\end{array}$ & 53 & 193 \\
\hline Exon 13 c-Kit & $\begin{array}{l}\text { Forward: 5'-GCT TGA CAT CAG TTT GCC AG-3' } \\
\text { Reverse: 5'-AAA GGC AGC TTG GAC ACG GCT TTA-3' }\end{array}$ & 66 & 193 \\
\hline Exon 14 c-Kit & $\begin{array}{l}\text { Forward: 5'-GTC TGA TCC ACT GAA GCT G-3' } \\
\text { Reverse: 5'-ACC CCA TGA ACT GCC TGT C-3' }\end{array}$ & 59 & 151 \\
\hline Exon 17 c-Kit & $\begin{array}{l}\text { Forward: 5'-TACAAG TTA AAA TGA ATT TAA ATG GT-3' } \\
\text { Reverse: 5'-AAG TTG AAA CTA AAA ACT CTT TGC-3' }\end{array}$ & 62 & 228 \\
\hline Exon 12 PDGFR-A & $\begin{array}{l}\text { Forward: 5'-TCC AGT CAC TGT GCT GCT TC-3' } \\
\text { Reverse: 5'-GCA AGG GAA AAG GGA GTC TT-3' }\end{array}$ & 61 & 260 \\
\hline Exon 14 PDGFR-A & $\begin{array}{l}\text { Forward: 5'-GTA GCT CAG CTG GAC TGA TA-3' } \\
\text { Reverse: 5'-AAT CCT CAC TCC AGG TCA GT-3' }\end{array}$ & 60 & 180 \\
\hline Exon 18 PDGFR-A & $\begin{array}{l}\text { Forward: 5'-TAC AGA TGG CTT GAT CCT GAG T-3' } \\
\text { Reverse: 5'-AGT GTG GGA GGA TGA GCC TG-3' }\end{array}$ & 65 & 211 \\
\hline
\end{tabular}

denaturing high-performance liquid chromatography (DHPLC) as described elsewhere (18). For each abnormal elution profile, genomic DNA was directly sequenced in both directions using a CEQ Dye-Terminator Cycle Sequencing kit (Beckman Coulter Inc., Miami, FL, USA) according to the manufacturer's protocol. The consent for investigation of blood samples was obtained according to the ethics requirement of our institute.

Multiplex ligation-dependent probe amplification (MLPA) analysis. Screening for the NFI single and multi-exon deletions was performed using the SALSA P081/082 NF1 V.04 MLPA assay (MRC-Holland, Amsterdam, The Netherlands), following the manufacturer's instructions. This assay consists of two reaction mixtures containing probes for all constitutive $N F 1$ exons, with the exception of exons 5, 7, 17, 19a, 45, and 47. An aliquot of $100 \mathrm{ng}$ of denatured genomic DNA was used in the overnight annealing of the exon-specific probes and subsequent ligation reaction. PCR was carried out with FAM-labeled primers using $10 \mu \mathrm{l}$ of ligation reaction. Separation and relative quantification of the amplification products were carried out using a Beckman CEQ 2000XL. The peak area for each fragment was measured and normalized by dividing it by the combined area of all peaks in that lane. This normalized peak area was then divided by the average normalized peak area from five normal controls. With this method, the results given are allele copy numbers compared with normal controls, and a ratio of $\sim 1$ should be obtained if both alleles are present. A reduction or increase in the peak area values to $<0.7$ or $>1.3$ was considered an indication of a deletion or a duplication, respectively.
DNA samples showing such a reduction or increase in the MLPA peak area values were reanalyzed by MLPA, and only the samples showing consistent results between the two experiments were considered positive for a deletion.

Real-time PCR. DNA copy-number changes identified by MLPA were confirmed using an ABI 7700 Sequence Detection System (Applied Biosystems) and the DNA-binding dye SYBR-Green (Applied Biosystems). To account for possible variations related to DNA input amounts or the presence of PCR inhibitors, the reference gene MEFV exon 5 was simultaneously quantified in a separate tube for each patient sample. SYBR-Green amplification mixtures $(25 \mu \mathrm{l})$ contained SYBR-Green master mix, $150 \mathrm{nmol} / 1$ of each forward and reverse primer, and $60 \mathrm{ng}$ of template DNA. The PCR cycling conditions were as follows: $2 \mathrm{~min}$ at $50^{\circ} \mathrm{C}, 2 \mathrm{~min}$ at $95^{\circ} \mathrm{C}, 40$ cycles of $95^{\circ} \mathrm{C}$ for $15 \mathrm{sec}$ and $60^{\circ} \mathrm{C}$ for $30 \mathrm{sec}$, and a final step at $72^{\circ} \mathrm{C}$ for $30 \mathrm{sec}$. After PCR amplification, a melting curve was generated for every PCR product to check the specificity of the PCR (absence of primer dimers or other non-specific amplification products). Each assay included a no-template control, $60 \mathrm{ng}$ of a normal control DNA used as a calibrator, and approximately $10 \mathrm{ng}$ of test DNA (in triplicate). Each sample was combined with two non-deleted negative controls (in triplicate). The threshold cycle $(\mathrm{Ct})$ values of SDS software V.2.3 (Applied Biosystems) were exported to Excel (Microsoft Corp., Seattle, WA, USA) for further analysis. The $\mathrm{Ct}$ calculation for the relative quantification of target was as follows: $\Delta \Delta \mathrm{Ct}=(\mathrm{Ct}$, target $N F 1$ exon - Ct, MEFV) $x$ - (Ct, target NF1 exon - Ct, MEFV)y, where $x$ unknown NF1 sample, and y calibrator. Results for 
Table III. Patients with GIST associated with other primary malignant and benign neoplasms.

\begin{tabular}{|c|c|c|c|}
\hline Patient no. & 1st tumor (age) & 2nd tumor (age) & 3rd tumor (age) \\
\hline 1 & GIST (78) & Adk rectum (78) & \\
\hline 2 & GIST (79) & Breast cancer (Paget) (79) & \\
\hline 3 & GIST (76) & Adk colon $(76)$ & \\
\hline 4 & Breast cancer (49) & GIST (67) & \\
\hline 5 & Adk stomach (75) & GIST (75) & \\
\hline 6 & GIST (78) & Kidney cancer (78) & \\
\hline 7 & GIST (81) & Kidney cancer (81) & \\
\hline 8 & Breast cancer (55) & GIST (72) & \\
\hline 9 & Kidney cancer (28) & GIST (35) & \\
\hline 10 & Breast cancer $(77)$ & GIST (79) & \\
\hline 11 & Breast cancer $(67)$ & GIST (77) & \\
\hline 12 & GIST (57) & Adk colon dx (57) & \\
\hline 13 & GIST (60) & Adk colon dx (60) & Cutaneous neurofibromas (40) \\
\hline 14 & GIST (78) & Adk stomach (78) & \\
\hline 15 & GIST (81) & Adk stomach (81) & \\
\hline 16 & GIST (77) & Adk colon $(77)$ & Hepatocellular carcinoma (77) \\
\hline 17 & Adk stomach (69) & GIST (69) & \\
\hline 18 & GIST (79) & Adk stomach (79) & \\
\hline 19 & GIST (69) & Breast cancer (79) & \\
\hline 20 & GIST (74) & Lung NSCLC (76) & Melanoma (77)/Aden parathyroid \\
\hline 21 & GIST (66) & Prostate cancer $(71)$ & \\
\hline 22 & GIST (55) & Adk colon $(62)$ & \\
\hline 23 & Ovarian cancer & GIST (75) & \\
\hline 24 & GIST (56) & Adk stomach (56) & \\
\hline 25 & Bladder cancer (64) & GIST (64) & \\
\hline 26 & GIST (65) & Adk colon $(66)$ & \\
\hline 27 & GIST (79) & Adk stomach (79) & \\
\hline 28 & ADK sigma (69) & GIST (77) & \\
\hline 29 & Ovarian (71) & GIST (71) & \\
\hline 30 & GIST (78) & Adk stomach (78) & MALT lymphoma (78) \\
\hline 31 & Urinary bladder (77) & GIST (78) & Adk stomach (78) \\
\hline 32 & GIST (48) & Apocrine cancer $(50)$ & \\
\hline 33 & GIST (72) & Thyroid cancer (63) & \\
\hline 34 & GIST (67) & Prostate cancer $(68)$ & \\
\hline 35 & GIST (74) & Adk colon $(74)$ & \\
\hline 36 & Papillarythyroid (68) & GIST (71) & Adk lung (76)/Liposarcoma \\
\hline 37 & LNH (80) & GIST (80) & \\
\hline 38 & GIST (58) & Kaposi's sarcoma (58) & \\
\hline 39 & Adk endometrial (34) & GIST (54) & Lung chondroma (54) \\
\hline 40 & GIST (32) & Lung chondroma (32) & \\
\hline 41 & Leiomyoma uterus (62) & GIST (70) & \\
\hline 42 & Leiomyoma stomach (54) & GIST (58) & \\
\hline 43 & GIST (58) & Leiomyoma stomach (60) & \\
\hline 44 & Leiomyoma stomach (67) & GIST (87) & \\
\hline 45 & Dermatofibromas (52) & GIST (69) & \\
\hline 46 & Colonic adenomas (49) & GIST (78) & \\
\hline
\end{tabular}

Adk, adenocarcinoma.

each sample were expressed in $\mathrm{N}$-fold changes in $x N F 1$ gene copies, and normalized to MEFV relative to the copy number of the NF1 gene in the calibrator according to the following equation: Amount of target $=2^{-\Delta \Delta C t}(19)$. A reduction in the peak area values to $<0.7$ was considered an indication of a deletion. 
A

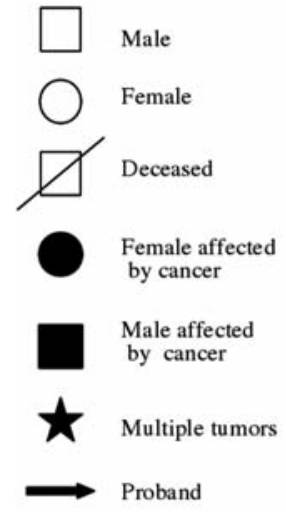

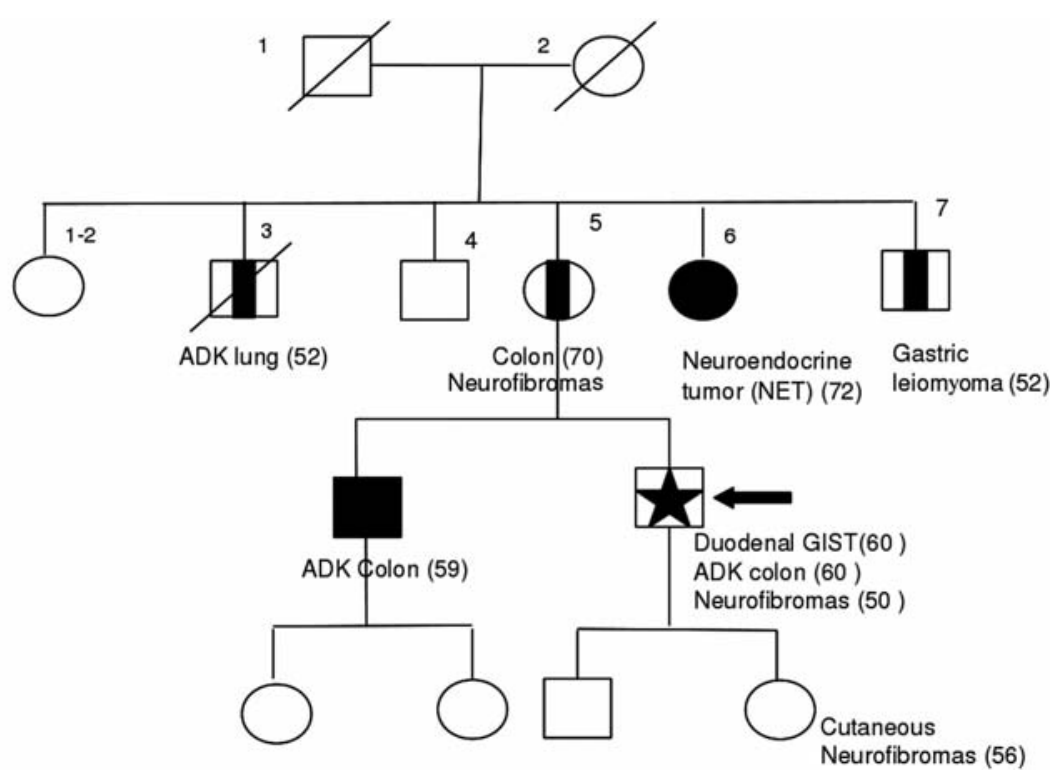

B

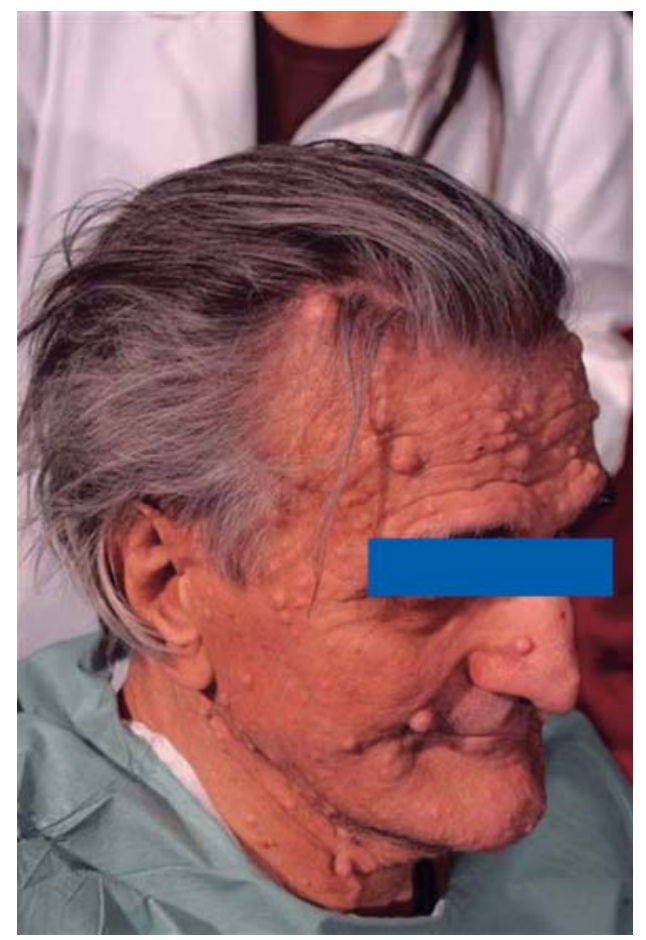

\section{Results}

One hundred and forty-one patients with GIST were identified, including 77 (54.6\%) men and $64(45.4 \%)$ women. GISTs occurred associated with other primary malignancies in 46 of 141 (32.6\%) patients occurring synchronously in half of the cases. In 11 cases $(24 \%)$, GISTs were diagnosed after another malignancy (mean, 5 years), and in 10 cases $(21.7 \%)$, the other malignancy was detected after GIST. The most common types of GISTassociated cancers were adenocarcinoma of the stomach $(9$ cases), adenocarcinoma of the colon (9 cases), renal carcinoma (4 cases) and breast cancers ( 6 cases). Eight of $141(5.6 \%)$ patients with GIST had a benign neoplasm including rare benign cutaneous neurofibromas, pulmonary

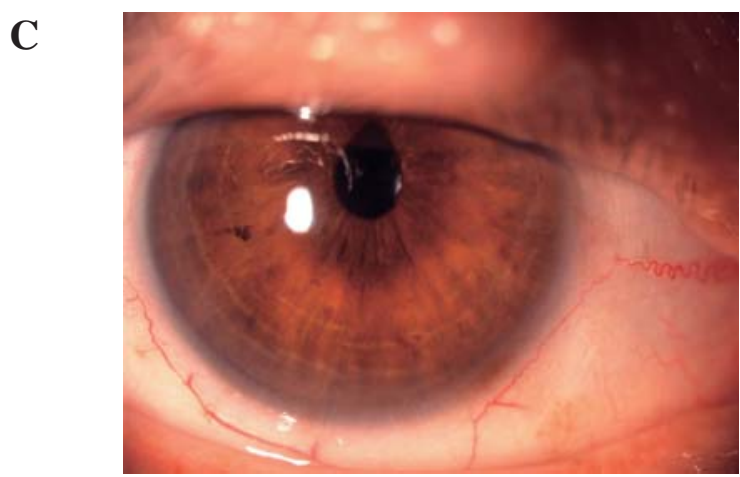

Figure 1. A family with GIST, NET and neurofibromas cosegregating NF1 exon 6 germline mutation. (A) Family pedigree; (B) clinical features of NF1/GIST proband; (C) Lisch nodes diagnosed in the proband.

hamartomas and gastrointestinal leiomyomas (Table III). The great majority of these GISTs were located in the stomach and small intestine. The group of 46 patients with a GIST and other neoplasms included 20 men (44\%) and 26 woman $(56 \%)$, with the mean age at diagnosis of 67 years, whereas the mean age in the group of patients with a GIST alone was 66 years. Seven GIST patients had a diagnosis of more than three neoplasms which were synchronous in three cases and metachronous in four. In a GIST patient, a gastric collision of three gastric tumors was diagnosed.

Gist and neurofibromas. One of the patients assessed was a 73-year old man with a history of type-1 neurofibromatosis. He had multiple cutaneous neurofibromas and $>6$ pigmented macules ranging up to $1 \mathrm{~cm}$ in diameter. At 50 years of age, the patient underwent left hemicolectomy for T3N0M0 well differentiated adenocarcinoma of the splenic flexure of the colon. During surgery, a small tumor was resected at the serosal side of the duodenum. Pathological examination showed GIST with very few mitoses $(<5$ per 50 high power fields). He had a brother and one daughter who were similarly affected by cutaneous neurofibromas. His brother, mother and two uncles all suffered from colon adenocarcinomas and neuroendocrine tumors (NET) (Fig. 1). 
A

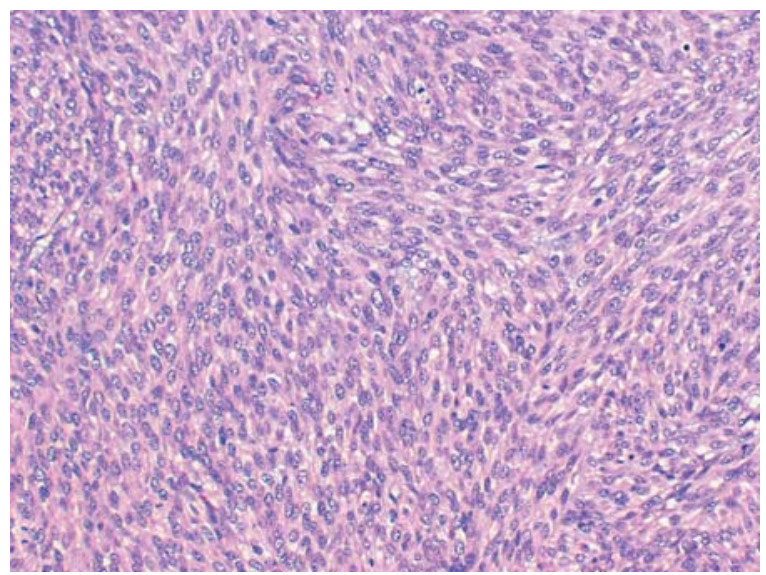

B

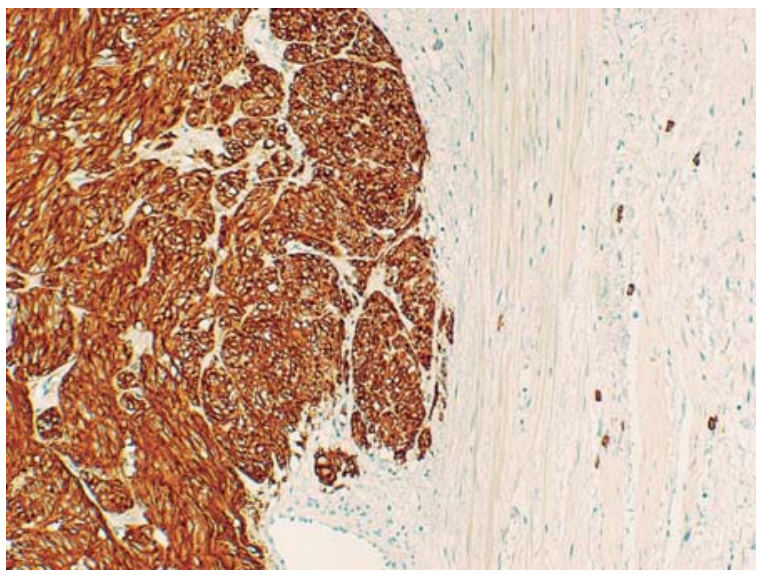

Figure 2. (A) Histological features of KIT-positive GIST (HE); (B) immunohistochemical features of C-KIT-positive GIST.

Gist and pulmonary chondroma. Two GIST patients presented synchronous diagnosis of suspected pulmonary chondroma responding to clinical definition of incomplete Carney Syndrome.

The first case recognized was a 54-year old woman with a history of endometrial carcinoma for which she underwent total hysterectomy at 34 years of age. She presented with a severe history of epigastric pain. Gastroscopy documented gastrohemorrhagic lesions and led to gastrectomy. An extramural gastric mass (diameter of $10 \mathrm{~cm}$ ) that appeared during surgery was resected and classified as infiltrating GIST with a low mitotic index. A pulmonary calcified and cystic nodule (diameter of $2 \mathrm{~cm}$ ) had been detected in a pre-operative chest X-ray and thoracic CT scan. Chondroma was defined on instrumental examination, which, with gastric GIST, was suggestive of incomplete Carney triad. Absence of a positive cancer history was documented among the first- and seconddegree relatives of the patient.

The second patient with features of incomplete Carney Syndrome was a 30-year old woman who underwent esophago-gastric resection for subcardial mass development $(5 \times 5 \mathrm{~cm})$ with resulting GIST with very low mitotic index. The synchronous diagnosis of a pulmonary calcified nodule (diameter of $2 \mathrm{~cm}$ ) was reported; both the X-ray and CT-scan evaluation suggested the radiological aspect of chondroma. The lesion was not operated and was stable in all instrumental follow-up evaluations. Histologically, the GISTs were predominantly epithelioid consisting of mildly to moderately atypical medium-sized polygonal cells. The proband's father had died of pancreatic cancer at 60 years of age; no other evidence of cancers in family members was documented.

Molecular studies. C-Kit somatic mutations were identified in $86 \%$ of the GIST patients whereas PDGFRA somatic mutations were found in about $11.4 \%$ of GIST patients. Less than $5 \%$ of GIST patients were negative for both C-Kit and PDGFRA mutations (Fig. 2).

GISTs associated with NF1 were negative for C-Kit and PDGFRA hot spot mutations. Immunostains of cutaneous neurofibroma tumor specimens were positive for S-100 proteins and negative for C-KIT, MLH1, and MSH2 proteins. The excised cutaneous neurofibroma from the proband was negative for KIT and PDGFRA somatic hot spot mutations. The blood specimen from the NF1 proband was negative for MLH1, MSH2, and C-KIT germline mutations and positive for the PDGFRA single nucleotide polimorphism 2472 $\mathrm{C}>\mathrm{T}$, leading to the sinonime variant Val824Val in exon 18. DHPLC analysis did not show any NF1 mutation in this patient. Then, in order to exclude intragenic insertions/ deletions, a SALSA P081/082 NF1 MLPA assay for NF1 copy-number changes was performed. The exon 6 electropherograms showed reductions of specific MLPA fluorescence signals compared with controls. After MLPA testing, this case showing an abnormal signal was reanalyzed by realtime PCR using SYBR-Green as the detection system. Single exon deletion was corroborated by a single real-time PCR assay corresponding to the deleted exon. The putative deletion identified by MLPA was confirmed by real-time PCR. A deletion of exon 6 was identified.

GIST associated with pulmonary chondroma was negative for S-100, C-KIT and PDGFRA mutations. The cytogenetic characterization of the atypical Carney triad patient showed a karyotype with sporadic translocation $(7 ; 14)(\mathrm{q} 32 ; \mathrm{q} 13)$. The same sporadic $7 \mathrm{q}$ deletion was identified in non-complex karyotypes of patients with gastric collision tumors (46, addXp), Y,del (3q), del (7q), add(20q) (Pz N³0).

\section{Discussion}

The analysis of synchronous and metachronous GISTassociated neoplasms among our cohort revealed a relatively high percentage of GIST patients with another diagnosed tumor and showed the crucial role of peculiar benign neoplasms in the identification of syndromic setting such as in Carney's Syndrome and von Recklinghausen disease usually not related to C-KIT and PDGFRA mutations. In the literature, the percentage of GIST patients with other diagnosed neoplasms ranged between 6 and 33\% $(5,17)$ and it has not been ascertained whether the coexistence of a GIST with other, unrelated syndromes or tumors is incidental or results from related pathophysiological processes. Half of the associated neoplasms were diagnosed synchronously with GIST, and in particular, with gastric GISTs-frequently discovered intraoperatively or incidentally during surgery or in the histopathological evaluation of gastric malignancy specimens. The most frequent of GIST-associated malignancies were 
the gastrointestinal and urological neoplasms. The association of gastric GIST and adenocarcinoma or mucosa-associated lymphoid tissue (MALT) lymphoma may be due to environmental or iatrogenic factors including Helicobacter pylori infection (18), dietary carcinogenesis and some drugs (19) that interact with the epithelial and stromal tissues in the stomach inducing the development of different neoplasms, and in addition, may be favored by a high incidence of tumors among the given population (20). Furthermore, it is possible that such an association may be caused by a single genetic aberration predisposing to the development of various histologic types of gastric neoplasms. Our evidence of germline NF1 large deletion linked to GIST and synchronous adenocarcinoma represents an example of genetic background of high individual and familial predisposition to multineoplastic disease.

Regarding the anatomic site, in accordance with previous evidence, the NF1-associated GIST was localized in the duodenum; this GI tract together with the jejunum are the typical sites of NF1-related GIST whereas sporadic GISTs are usually localized in the stomach. The histological features of NF1-associated GISTs are very similar to those of nonNF1-associated GIST, but characteristically, most of the NF1-associated GIST contained skenoid fibers (11). It is known that somatic NF1 inactivation is involved in neoplastic GIST cells where the lack of functional neurofibromin, in the absence of KIT or PDGFRA mutations, can lead to GIST development. However, due to the wide variation in expression of the disease, observed even among family members carrying the same NF1 mutation, it has been hypothesized that mutations in genes other than NF1 may be necessary for the development of the full phenotype. A biomolecular and clinical overlap between PDGFRA/KIT and NF1/NF3 neurofibromatosis is documented and needs further investigation. Recently, a germline PDGFRA mutation has been detected in a GIST patient affected by intestinal neurofibromatosis and multiple gastric GISTs; in this family with germline PDGFRA (Y555C) (12), as well as in other known kindred affected by germline PDGFRA mutation (B846Y) (21), the affected family members have large hands, broad wrists and a coarse face as peculiar clinical features. We found that the NF1 exon 6 large deletion was associated with an aggressive and complex phenotype including either all of the clinical features of type 1 neurofibromatosis or some peculiar morpho-constitutional features associated with germline PDGFRA mutations $(12,21)$ in the proband and in two first-degree relatives who also developed gastrointestinal adenocarcinomas and carcinoid tumors (Fig. 1). Despite the search for hot spots PDGFRA mutation was negative, showing only exon 18 polymorphism, the similarity of clinical features, particularly the large hands and coarse face, of our NF1/ GIST patient and germline PDGFRA mutation carrier patients suggests that further studies are needed to characterize the role of NF1 exon 6 large deletion, the potential genotypephenotype correlation and other functional overlaps among NF1 and specific PDGFRA polymorphisms or mutations.

Carney's Syndrome is another disease where GIST and other benign neoplasms coexist and is characterized by the association of at least two tumors, an extra-adrenal paraganglioma or pulmonary chondroma, with GIST usually localized in the stomach. To date, about 80 cases of Carney's triad and a similar number of apparently sporadic pediatric GISTs have been reported (22). Peculiar features of CarneyGISTs are the presentation in early adult life, a striking female predilection $(>80 \%)$, predominantly epithelioid morphology, location in the stomach (antrum) and lack of C-KIT and PDGFRA mutations. Both of the Carney's patients in this study demonstrated all of these traits, being young women with gastric C-KIT and PDGFRA-negative GISTs presenting an indolent course. Recently, germline mutations of the genes encoding succinate dehydrogenase subunits B, C and D have been described in the inherited dyad of paraganglioma and gastric stromal tumors or Carney-Stratakis Syndrome (23).

Regarding the coexistence of GIST and renal carcinomas in one study, papillary renal cell carcinomas were significantly associated with GISTs (24). In particular, these neoplastic associations were found linked to mutation of proto-oncogenes coding tyrosine kinase C-KIT and C-MET. Two cases of clear cell renal carcinoma coexisting with GIST in the setting of Von Hippel-Lindou disease and one in an atypical variant of Carney's triad, respectively, have been reported $(24,25)$. Among our three GIST patients who developed clear cell renal carcinoma, one (Table III) presented at a very early age with diagnosis of both GIST and clear cell renal carcinoma, thus showing a cancer's family history positive for early onset breast cancer.

In conclusion, the evidence of the current study can be summarized as follows: first, on a clinical basis, the development of GIST associated with other neoplasms is common and diagnosis warrants the search for associated familial cancer susceptibility; therefore, an accurate personal and family history should be viewed as a critical step for proper diagnosis of the disease. Second, among the C-KIT and PDGFRA-negative GIST patients, the rare neurofibromas and pulmonary chondromas can represent the benign stigmata of syndromal setting, thus allowing clinicians to tailor a familial screening program for visceral disease in high-risk individuals; these findings confirm that NF1 and Carney triad-related GISTs differ from sporadic GISTs in both their clinico-pathological and molecular profiles. Third, the role of alternative oncogenes, other than KIT and PDGFRA, in GIST tumorigenesis and in the multi-neoplastic and familial setting also remains to be identified for novel target-therapy development. Overall, the current findings reveal that the coexistence of GIST and other primary neoplasms constitute an intriguing oncologic model for both the recognition of syndromic setting and novel drug targets for experimental pharmacological research.

\section{References}

1. Miettinen M, Majidi M and Lasota J: Pathology and diagnostic criteria of gastrointestinal stromal tumors (GISTs): a review. Eur J Cancer 38: 39-51, 2002.

2. Fletcher CD, Berman JJ, Corless C, Gorstein F, Lasota J, Longley BJ, Miettinen M, O'Leary TJ, Remotti H, Rubin BP, Shmookler B, Sobin LH and Weiss SW: Diagnosis of gastrointestinal stromal tumors: a consensus approach. Hum Pathol 33: 459-465, 2002.

3. Corless CL, McGreevey L, Haley A, Town A and Heinrich MC: KIT mutations are common in incidental gastrointestinal stromal tumors one centimeter or less in size. Am J Pathol 16: 1567-1572, 2002. 
4. Hirota S, Isazaki K, Moriyama Y, Hashimoto K, Nishida T, Ishiguro S, Kawano K, Hanada M, Kurata A, Takeda M, Muhammad Tunio G, Matsuzawa Y, Kanakura Y, Shinomura Y and Kitamura Y: Gain-of-function mutations of C-KIT in human gastrointestinal stromal tumor. Science 279: 577-580, 1998.

5. Agaimy A, Wunsch PH, Sobin LH, Lasota J and Miettinen M: Occurrence of other malignancies in patients with gastrointestinal tumors. Sem Diagn Pathol 23: 120-129, 2006.

6. Liszka L, Zielinska-Pajak E, Pajak J, Golka D and Huszno J: Coexistence of gastrointestinal stromal tumor with other neoplasms. J Gastroenterol 42: 641-649, 2007.

7. Blay JY, Bonvalot S, Casali P, Choi H, Debiec-Richter M, Dei Tos AP, Emile JF, Gronchi A, Hogendoorn PC, Joensuu H, Le Cesne A, McClure J, Maurel J, Nupponen N, Ray-Coquard I, Reichardt P, Sciot R, Stroobants S, van Glabbeke M, van Oosterom A and Demetri GD: GIST consensus meeting panelists. Consensus meeting for the management of gastrointestinal stromal tumors. Report of the GIST Consensus Conference of 20-21 March 204, under the auspices of ESMO. Ann Oncol 16: 566-578, 2005.

8. Carney JA: Gastric stromal sarcoma, pulmonary chondroma, and extra-adrenal paraganglioma (Carney Triad): natural history, adrenocortical component, and possible familial occurrence. Mayo Clin Proc 74: 543-552, 1999.

9. Miettinen M, Fetsch JF, Sabin LH and Lasota J: Gastrointestinal stromal tumors in patients with neurofibromatosis 1: a clinicopathological and molecular genetic study of 45 cases. Am J Surg Pathol 30: 90-96, 2006.

10. National Institute of Health Consensus Development conference statement: Neurofibromatosis. Arch Neurol 45: 575-578, 1988.

11. Takazawa Y, Sakurai S, Sakuma Y, Ikeda T, Yamaguchi J, Hashizume Y, Yokoyama S, Motegi A and Fukayama M: Gastrointestinal stromal tumors of Neurofibromatosis type 1 (von Recklingausen disease). Am J Surg Pathol 29: 759-763, 2005.

12. De Raedt T, Cools J, Debiec-Rychter M, Brems H, Mentens N, Sciot R, Himpens J, de Wever I, Schoffski P, Marynen P and Legius E: Intestinal neurofibromatosis is a subtype of Familial GIST and results from a dominant activating mutation in PDGFRa. Gastroenterology 131: 1907-1912, 2006.

13. Warren $\mathrm{G}$ and Gates O: Multiple primary malignant tumors. A survey of the literature and a statistical study. Am J Cancer 16: $1358-1414,1932$.

14. De Luca A, Bottillo I, Dasdia MC, Morella A, Lanari V, Bernardini L, Divona L, Giustini S, Sinibaldi L, Novelli A, Torrente I, Schirinzi A and Dallapiccola B: Deletions of NF1 gene and exons detected by multiplex ligation-dependent probe amplification. J Med Genet 44: 800-808, 2007.
15. De Luca A, Schirinzi A, Buccino A, Bottillo I, Sinibaldi L, Torrente I, Ciavarella A, Dottorini T, Porciello R, Giustini S, Calvieri S and Dallapiccola B: Novel and recurrent mutations in the NF1 gene in Italian patients with neurofibromatosis type 1. Hum Mutat 23: 629, 2004.

16. Livak KJ and Schmittgen TD: Analysis of relative gene expression data using real-time quantitative PCR and the 2(-Delta Delta C(T)) method. Methods 25: 402-408, 2008.

17. Ruka A, Rutkowski P, Nowecki Z, Nasierowska-Guttmejer A and Debiec-Rychter M: Other malignant neoplasms in patients with gastrointestinal stromal tumors (GIST). Med Sci Monit 10: 13-14, 2004.

18. Kaffes A, Hughes L, Hollinshead J and Katelaris P: Synchronous primary adenocarcinoma, mucosa-associated lymphoma tissue lymphoma and stromal tumor in a Helicobacter Pylori infected stomach. J Gastroenterol 35: 332-334, 2002.

19. Cohen A, Geller SA, Horowitz I, Toth LS and Werther JL: Experimental models for gastric leiomyosarcoma: the effect of $\mathrm{N}$-methyl-N-nitro-nitrosoguanidine in combination with stress, aspirin, or sodium taurocholate. Cancer 53: 1088-1092, 1984.

20. Maiorana A, Fante R, Maria Cesinaro A and Adriana Fano R: Synchronous occurrence of epithelial and stromal tumors in the stomach. Arch Pathol Lab Med 124: 682-686, 2000.

21. Chompret A, Kannengiesser C, Barrois M, Terrier P, Dahan P, Tursz T, Lenoir GM and Bressac-De Paillerets B: PDGFR $\alpha$ germ-line mutation in a family with multiple cases of gastrointestinal stromal tumor. Gastroenterology 126: 318-321, 2004.

22. Agaram NP, Laquaglia MP, Ustun B, Guo T, Wong GC, Socci ND, Maki RG, DeMatteo RP, Besmer P and Antonescu CR: Molecular characterization of pediatric gastrointestinal stromal tumors. Clin Cancer Res 14: 3204-3215, 2008.

23. Pasini B, McWhinney SR, Bei T, Matyakhina L, Stergiopoulos S, Muchow M, Boikos SA, Ferrando B, Pacak K, Assie G, Baudin E, Chompret A, Ellison JW, Briere JJ, Rustin P, Gimenez-Roqueplo AP, Eng C, Carney JA and Stratakis CA: Clinical and molecular genetics of patients with the CarneyStratakis syndrome and germline mutations of the genes coding for the succinate dehydrogenase subunits SDHB, SDHC and SDHD. Eur J Hum Genet 16: 79-88, 2008.

24. Au WY, Ho KM and Shek TW: Papillary renal carcinoma and gastrointestinal stromal tumor: a unique association. Ann Oncol 15: 843-844, 2004.

25. Tzankov A, Schwanninger J, Mikuz G and Mairinger T: Atypical Carney's triad with coincidental clear cell renal carcinoma in an 84-year old patient. A finding at autopsy. Cancer Detect Prev 27: 256-258, 2003 